\title{
A Humanização do Sistema de Justiça por meio do Depoimento Especial: Experiências e Desafios
}

\author{
Cátula Pelisoli - Tribunal de Justiça do Rio Grande do Sul, Comarca de Passo Fundo, Brasil \\ Débora Dalbosco Dell'Aglio - Universidade Federal do Rio Grande do Sul, Porto Alegre, Brasil
}

\begin{abstract}
Resumo
O Depoimento Especial (DE) é uma prática de escuta de crianças e adolescentes vítimas de abuso sexual que objetiva minimizar os danos causados por recorrentes testemunhos. O objetivo deste trabalho foi verificar a percepção de trabalhadores do Poder Judiciário sobre o DE, com foco na atuação do psicólogo, a partir de entrevistas com 20 profissionais do Estado do Rio Grande do Sul com experiência nesse método. A análise de conteúdo das entrevistas, com apoio do software webQDa, evidenciou três categorias (Papel do entrevistador, Funções do DE e Condições técnicas). Os resultados indicaram que diferentes profissionais podem exercer essa atividade e que a autonomia do entrevistador é dependente dos operadores com quem trabalha. O DE possui as funções tanto de comprovação do fato como de proteção e a experiência tem propiciado o aperfeiçoamento do método, ainda que sejam necessárias melhorias. O DE é um método em construção, dependente de seus trabalhadores e pleno de possibilidades de aperfeiçoamento.

Palavras-chave: abuso sexual, psicologia jurídica, maus tratos infantis
\end{abstract}

\section{Humanization of justice system by Special Testimony: Experiences and challenges}

\begin{abstract}
The Special Testimony (ST) is a practice of inquiry for children and adolescents victims of sexual abuse that aims to minimize negative consequences related to repetitive testimonies. The objective of this study was to verify perceptions of Law workers about ST, focusing on the psychologist work, from interviews with 20 professionals' experts in this method. The content analysis with WebQda showed three categories (Role of Psychology, Functions of ST and Technical conditions). The results indicated that different professionals can execute this activity and the autonomy of interviewer is dependent on workers. The functions of ST are not only the proof of the fact but also its protection. Workers indicate the experience has been positive and it has propitiated the improvement of the method, but technical improvements are still necessary. ST is still a method under construction, dependent on workers and full of possibilities of changes.
\end{abstract}

Keywords: sexual abuse, forensic psychology, child abuse

\section{Humanización del sistema de justicia por medio del Testimonio Especial: Experiencias y desafíos}

\section{Resumen}

El Testimonio Especial (TE) es una práctica de indagación de niños y adolescentes víctimas de abuso sexual, cuyo objetivo es minimizar los daños causados por recurrentes testimonios. El objetivo de este trabajo fue verificar la percepción de trabajadores del Poder Judicial sobre el TE, centrándose en el trabajo de psicólogos, a partir de entrevistas con 20 profesionales del Estado de Río Grande del Sur con experiencia en ese método. El análisis de contenido de las entrevistas, con apoyo del software webQDa, evidenció tres categorías (Papel del entrevistador, Funciones del TE y Condiciones técnicas). Los resultados indicaron que diferentes profesionales pueden ejercer esa actividad y que la autonomía del entrevistador depende de los operadores con quien trabaja. El TE contiene funciones tanto de comprobación del hecho como de protección, y la experiencia contribuyó para el perfeccionamiento del método, aunque sean necesarias mejorías. El TE es un método en construcción, dependiente de sus trabajadores y con muchas posibilidades de perfeccionamiento.

Palabras clave: abuso sexual, psicología jurídica, abuso infantil

A escuta de crianças e adolescentes que sofreram abuso sexual não é tarefa fácil para nenhum profissional (Hoffmeister, 2012). Com frequência, vários atores são chamados a participar e intervir nessas situações: conselheiros tutelares, assistentes sociais, psicólogos, médicos, enfermeiros, policiais e outros operadores da lei (Faller, 2007a). Uma vez que se trata de crime caracterizado, geralmente, pela não materialidade do fato, a palavra da (suposta) vítima torna-se, na maior parte dos casos, a principal forma de acessar os fatos (Dammeyer,
1998; Finnilã-Tuohimaa et al., 2005; Herman, 2010; Stein, Pergher, \& Feix, 2009). Tendo em vista a necessidade de atuação de diferentes áreas e a complexidade e interdisciplinaridade contida no problema, atualmente se tem pensado em metodologias que visam a reduzir a quantidade de pessoas e situações de escuta da criança, com a intenção prioritária da proteção integral e não revitimização (Brasil, 1990a).

A revelação do abuso, por exemplo, pode ocorrer tanto em um contexto clínico como em um contexto 
forense (Faller, 2007a), e a entrevista é a principal estratégia para acessar a suposta vítima e avaliá-la. Essa avaliação, porém, tem objetivos bem diferentes, dependendo do contexto em que é realizada (Faller, 2007a; Huss, 2011). Em primeiro lugar, o "cliente" no contexto forense é o próprio sistema de justiça, enquanto que, na clínica, é a criança ou o membro da família em atendimento. Outra diferença diz respeito à neutralidade do profissional no contexto forense: o profissional não deve ter interesse prévio em provar se o abuso ocorreu ou não. Além disso, o foco na justiça é nos fatos que ocorreram, enquanto o foco do clínico é em como esses fatos afetaram a vítima. Essas diferenças vão implicar no uso de estratégias diversas de entrevista e de manejo das situações (Faller, 2007a).

Uma estratégia que tem sido utilizada em entrevistas no contexto forense é a videogravação (Myers, 1998), considerada a forma mais completa de documentação da entrevista, fornecendo informações verbais e visuais sobre o que aconteceu durante o tempo de avaliação (Faller, 2007b). As vantagens de seu uso são: a) redução do número de entrevistas e/ou do número de entrevistadores; b) documentação completa da entrevista; c) possibilidade de substituição do testemunho da criança numa audiência tradicional; d) contribuição para $\mathrm{O}$ entrevistador relembrar o seu conteúdo antes de servir como testemunha em uma audiência; e) pode ser utilizada para persuadir um cuidador não abusivo que não está acreditando na revelação; f) pode ser utilizada para persuadir o agressor a confessar seu crime; g) peritos em abuso sexual podem assistir ao vídeo para formar uma opinião sobre o caso; h) o vídeo preserva a revelação inicial; i) pode ser utilizado para supervisão e j) é mais persuasivo do que o testemunho do entrevistador sobre o que a criança disse. Entretanto, existem desvantagens: a) a existência de inconsistências no depoimento pode ser motivo de contestação em audiência; b) a técnica do entrevistador pode ser também motivo de contestação; c) gravar pode deixar a criança desconfortável; d) vídeos de baixa qualidade podem não deixar os dados claros; e) as gravações podem ser realizadas/mantidas por pessoas não confiáveis, que não vão garantir a confidencialidade dos dados; f) as crianças podem modificar seus comportamentos por estarem sendo filmadas (Myers, 1998).

A videogravação de entrevistas de crianças e adolescentes vítimas de abuso sexual tem ocorrido há pouco tempo dentro do Poder Judiciário brasileiro. Inicialmente denominado "Depoimento Sem Dano", o Depoimento Especial - DE propõe retirar as crianças e adolescentes vítimas de abuso sexual do ambiente formal da sala de audiências e transferi-las para uma sala especialmente projetada, com recursos audiovisuais e um profissional especializado (Daltoé Cezar, 2007). Os objetivos do método são reduzir o dano à criança e ao adolescente vítima, garantir os direitos, proteger e prevenir, e melhorar a produção da prova (Daltoé Cezar, 2007). O DE é, atualmente, uma recomendação do Conselho Nacional de Justiça - CNJ (2010). Na Resolução 33/2010, o CNJ considerou documentos como a Constituição Federal (Brasil, 1988), o Estatuto da Criança e do Adolescente (Brasil, 1990a) e a Convenção Internacional Sobre os Direitos da Criança (Brasil, 1990b) para recomendar a implantação de salas de depoimento videogravado para crianças e adolescentes. Nesse documento, justifica-se a recomendação por meio do interesse prioritário pela criança, do direito da criança e do adolescente de serem ouvidos em processos judiciais de seu interesse e de terem sua opinião considerada. O CNJ considera que o sistema de justiça necessita de provas testemunhais mais confiáveis para a responsabilização de agressores e indica a importância de preservar as crianças e adolescentes nessas situações. Dessa forma, o DE deve acontecer em espaço adequado e com profissional capacitado para acolher, orientar e encaminhar as pessoas, de acordo com suas necessidades.

O método de escuta protegida de crianças vítimas pelo Poder Judiciário tomou proporções grandiosas, tanto em sua expansão quanto pelas críticas recebidas. Em diversos países, essa prática já é reconhecida e institucionalizada (Santos \& Gonçalves, 2008). Entretanto, no Brasil, o DE tem enfrentado duras críticas e ainda não se configura como uma prática aceita por todas as categorias profissionais envolvidas. Assistentes sociais e psicólogos, aqueles que seriam, em tese, os principais entrevistadores das crianças e adolescentes vítimas, têm opiniões divergentes sobre a tarefa: enquanto os conselhos federais são contrários à prática (Conselho Federal de Psicologia, 2010; Conselho Federal de Serviço Social, 2009), algumas associações, sociedades e outras instituições são favoráveis (Estado do Rio Grande do Sul, 2010). Esses dois polos opostos não têm encontrado um diálogo intermediário para que a real proteção a crianças e adolescentes seja possível.

Aqueles que são favoráveis entendem que a escuta no sistema judiciário é um direito fundamental da criança (Froner \& Ramires, 2008) e que, comparado às audiências tradicionais, o DE oferece um atendimento mais humanizado e que possibilita o exercício 
da cidadania (Wolff, 2008). O próprio surgimento dessa metodologia foi devido à percepção, por promotores de justiça e juízes, de que a audiência tradicional podia ser caracterizada como uma revitimização (Dobke, 2001; Tabajaski, Paiva \& Visnievski, 2010). Os argumentos favoráveis incluem o fato de que, muitas vezes, a prova testemunhal é a única possível de ser produzida e que o ambiente da sala tradicional de audiências não é adequado para ouvir crianças e adolescentes (Froner \& Ramires, 2008). Aliás, anteriormente à prerrogativa do Depoimento Sem Dano, as normas e procedimentos de inquirição eram os mesmos utilizados com adultos (Dobke, 2001; Potter, 2010), desconsiderando quaisquer necessidades específicas daquela população. Hoffmeister (2012) entende que quando o sistema de justiça possibilita uma condição especial para o depoimento de crianças e adolescentes significa valorizar sua palavra e respeitá-los enquanto sujeitos de direitos. Atualmente, com a recomendação pelo Conselho Nacional de Justiça, o DE não é somente uma possibilidade, mas uma prática que deve ser institucionalizada como norma no país (Conselho Nacional de Justiça, 2010).

Aqueles que são contrários afirmam que essa escuta não é exatamente um direito da criança, mas um dever (Conselho Federal de Psicologia, 2008) e uma obrigatoriedade que é imputada a ela de dizer a verdade (Conte, 2008). Alguns autores entendem que duas realidades diferentes entram, neste contexto, em oposição: a realidade psíquica e a realidade factual. Para Conte (2008), insistir no relato objetivo (realidade factual) pode causar dano psíquico, enquanto somente a escuta (da realidade psíquica) possibilita a recomposição simbólica. Dessa forma, Conte (2008) conclui que a prática do psicólogo se insere na segunda perspectiva, concordando com o Conselho Federal de Psicologia (2008), quando este diz que o psicólogo, nestes procedimentos, "está fora de seu verdadeiro papel” (p.10). De acordo com essa opinião, há um distanciamento entre o que seria um trabalho para o profissional de Psicologia e a realização de audiências e coleta de testemunhos, uma vez que não há objetivo, nesse procedimento, de avaliação psicológica, atendimento ou encaminhamento (Brito, 2008). No DE, conforme Brito (2008), não há tempo para entrevistas com outras pessoas envolvidas ou estudos psicológicos e, além disso, pode se revelar prejudicial à criança. Além disso, o Conselho Federal de Psicologia entende que o DE "ignora a função do psicólogo” (p.10) e afirma que o psicólogo é usado para punir o maltratante, que tem relação de afeto com a criança (Conselho Federal de Psicologia, 2008). Afirma ainda que a metodologia é "supostamente humanizada", tendo em vista que o profissional não é chamado a realizar uma intervenção, mas a atuar como mediador para o inquiridor (juiz). É importante considerar, entretanto, que os textos publicados, em sua maioria, retratam opiniões técnicas e não necessariamente dados empíricos. Neste tema, há uma carência evidente de estudos que possam lançar luz a essa questão e contribuam para a resolução dessas ambiguidades.

Fato é que o DE é, atualmente, um sistema estabelecido, ainda que com opiniões divergentes a seu respeito. No entanto, poucos estudos buscam saber empiricamente como tem sido utilizada e quais as repercussões dessa estratégia para os envolvidos. Profissionais, famílias e as próprias vítimas podem e devem ser participantes de estudos que busquem verdadeiramente conhecer o método, em suas forças e fraquezas. Partindo do pressuposto de que não há ninguém que conheça tão bem essa metodologia quanto aqueles que atuam diariamente com ela, este estudo teve o objetivo de identificar as percepções dos trabalhadores da Justiça sobre o DE.

\section{Método}

\section{Delineamento}

Este é um estudo de caso coletivo (Stake, 1994) envolvendo servidores da Justiça no âmbito do Estado do Rio Grande do Sul.

\section{Participantes}

Foram entrevistados 20 profissionais vinculados ao Poder Judiciário (cinco juízes de direito, cinco promotores de justiça, cinco defensores públicos e cinco psicólogas), os quais tiveram atuação em casos de abuso sexual infantil com a utilização da metodologia do DE. Estes profissionais são provenientes de cinco municípios do Estado do Rio Grande do Sul.

\section{Instrumentos}

Foram utilizados dois protocolos de entrevista semiestruturada, elaborados para este projeto de pesquisa. Um protocolo foi utilizado para os operadores do Direito e outro para as psicólogas judiciárias, sendo que ambos investigavam as opiniões dos entrevistados sobre o DE, funções e objetivos, a relação do profissional de Psicologia e suas competências e habilidades. As questões propostas às diferentes categorias foram semelhantes, com apenas algumas adaptações. Algumas questões utilizadas com todos os participantes foram: 
"Nos casos que você acompanhou, quais foram os resultados positivos e negativos do Depoimento Especial?"; "Você teve oportunidade de acompanhar casos similares que não passaram pelo $\mathrm{DE}$, mas por audiência tradicional? Como você poderia comparar esses dois procedimentos?"; "Quais são os requisitos/conhecimentos necessários para atuar na escuta da criança?". Por sua vez, com as psicólogas foi questionado: "Como se dá a relação com os operadores do direito? Você tem autonomia e poder para modificar uma pergunta ou não fazê-la caso considere desnecessária ou inadequada?". Já com os operadores do Direito, algumas questões foram: "Quem você considera ser os profissionais mais qualificados para a tarefa de ouvir judicialmente as crianças e adolescentes vítimas?”; "Quais são os requisitos/conhecimentos necessários para atuar na escuta da criança?"; "Como se dá a relação com o psicólogo no DE? Ele tem autonomia e poder para modificar uma pergunta ou não fazê-la caso considere desnecessária ou inadequada?"

\section{Procedimentos}

A seleção dos participantes se deu a partir da identificação das cidades no Estado do Rio Grande do Sul que possuíam duas condições simultâneas: 1) salas de depoimento especial e 2) psicólogos em sua equipe (cinco municípios). No sentido de garantir o anonimato dos participantes, que exercem funções específicas e únicas nessas localidades, os municípios não serão identificados. A duração das entrevistas variou de 15 minutos a mais de uma hora, com uma média de 40 minutos. Todos os participantes aceitaram prontamente a participação na pesquisa, tendo assinado o Termo de Consentimento Livre e Esclarecido (Resolução no 466, Brasil, 2012)). Este projeto teve aprovação prévia do Comitê de Ética do Instituto de Psicologia da Universidade Federal do Rio Grande do Sul, sob o protocolo de número 20698.

\section{Análise de Dados}

Os dados foram armazenados em arquivos digitais e transcritos pela equipe de pesquisa para a análise qualitativa. Foi utilizado o software webQDA para a sistematização da análise de conteúdo. As entrevistas foram analisadas, inicialmente, considerando-se as categorias profissionais. No entanto, não foram observadas diferenças que justificassem uma análise por categorias profissionais, e dessa forma, chegou-se à formulação de categorias gerais, que englobam as respostas de todos participantes. As categorias foram levantadas a posteriori
(Bardin, 1977). O webQDA é um software destinado à análise de dados qualitativos, que possui mecanismos de armazenamento, pesquisa e recuperação de dados (Souza, Costa, \& Moreira, 2011). O software permite a visualização e discussão dos dados de pesquisa e da categorização por pesquisadores, de forma simultânea, possibilitando uma análise interativa e uma construção colaborativa do conhecimento e, especialmente, a validação dos processos de categorização (Souza et al., 2011). Portanto, o softwware não realiza a categorização de forma automática, apenas facilita a administração das informações pelos pesquisadores.

\section{Resultados}

$\mathrm{Na}$ apresentação dos resultados, os participantes serão identificados pelos seguintes códigos alfabéticos: defensores públicos (D), promotores de justiça (Pro), juízes de direito (J) e psicólogas judiciárias (Psi); e as cidades serão numeradas de um a cinco (1-5). As categorias e subcategorias, resultantes da análise de conteúdo foram: (a) Papel da Psicologia: competência da Psicologia; autonomia; (b) Funções do depoimento especial: produção da prova, proteção da vítima; e c) Condições técnicas: equipamento e espaço físico, experiência prática.

\section{a) Papel da Psicologia:}

Essa categoria descreve as percepções dos participantes sobre as competências e possibilidade de autonomia do psicólogo no DE. Quanto à competência da Psicologia, defensores, promotores e juízes reconhecem a possibilidade de outros profissionais atuarem no $\mathrm{DE}$, como psiquiatras, assistentes sociais e profissionais da educação. Porém, a maior parte dos entrevistados considera que a Psicologia é a área de conhecimento com maiores condições de contribuir para essa prática. Os entrevistados afirmam que suas experiências com a participação de psicólogos têm demonstrado que eles apresentam conhecimentos diferenciados, técnica para inserir a pergunta em um contexto adequado e também sensibilidade e habilidade para conquistar a confiança do entrevistado, aspectos que contribuem para o trabalho no DE.

Alguns participantes (dois promotores de justiça, uma defensora e um juiz) consideram que a formação em nível de graduação é menos importante do que um treinamento específico posterior e as características da pessoa do entrevistador: "Eu acho que independente de qualquer coisa tem que ter muita sensibilidade" 
(D4). Também nesse sentido, uma promotora afirma: "Eu não diria que a criança está resguardada simplesmente pela questão de ser um psicólogo. Eu acho que a criança está resguardada pela questão de ser um psicólogo capacitado" (Pro4). Dessa forma, é possível concluir que não basta ser psicólogo, mas também há a necessidade de formação/treinamento específico e habilidades pessoais que contribuam para a tarefa.

As psicólogas judiciárias concordam que o preparo para a tarefa específica se sobrepõe à formação. As profissionais veem a possibilidade de advogados, psiquiatras, pedagogos, além de assistentes sociais e dos próprios psicólogos, atuarem no DE, desde que tenham treinamento para a condução da entrevista. Para uma psicóloga: "Se a gente como profissional tá sendo chamado pra isso eu acho que a gente não pode se omitir" (Psi5). Entretanto, não são todos os psicólogos que devem assumir o exercício dessa complexa atividade. Além da capacitação adequada, é esperado que este tenha sensibilidade para acolher crianças e adolescentes vítimas de uma forma cuidadosa.

Uma questão controversa observada foi referente à possibilidade de autonomia dos entrevistadores para modificar ou não fazer perguntas que tenham sido solicitadas. Por exemplo, há profissionais que consideraram que o entrevistador não deve mudar em nada os questionamentos já deferidos pelo juiz, o que significaria uma ausência total da autonomia do entrevistador. Uma defensora afirmou efusivamente: "A psicóloga não tem e nem pode ter, no meu ponto de vista, autonomia para ficar modificando ou acrescentando pergunta!" (D3). Nesse caso, o entrevistador seria um reprodutor de questões deferidas pelo juiz. No entanto, outros entrevistados consideraram que o psicólogo/entrevistador pode e deve adaptar a questão à situação e condição da criança, mas deve buscar obter seu conteúdo, o que pode ser caracterizado como uma autonomia limitada: "O psicólogo tem que dar um jeito de conseguir introduzir essa pergunta na mesma conversa, nem que seja modificando um pouco, mas o conteúdo tem que ser extraído" (D1), ou ainda "Eu entendo que ela não pode não fazer a pergunta, agora, a adaptação da pergunta eu acho que é tranquilo" (Pro1). Um juiz considerou que esta possibilidade é o diferencial do DE: "Isso é o que eu acho mais interessante no sistema, essa reformulação da pergunta" (J4). Não foi observado posicionamento diferente em relação a essa questão nas diferentes categorias profissionais e houve predominância da ideia de que o entrevistador tem o dever de obter as respostas para as questões formuladas pelos operadores, mas com a possibilidade de modificação para uma maior adequação às circunstâncias do caso.

Houve também profissionais que consideraram que o psicólogo deve ter total autonomia: "Eu acho que a autonomia do psicólogo nessas questões teria que ser irrestrita, porque é o profissional adequado para esse tipo de situação, inclusive no sentido de dizer "não, esse tipo de pergunta vai gerar uma situação assim, então vou fazer de outra forma" ou, enfim, até para orientar" (D4). Essa opinião foi pouco comum, mas houve profissionais de todas as categorias que indicaram que o entrevistador poderia e deveria negar-se a realizar determinados questionamentos à vítima. Para esses profissionais, ainda que exista um sistema presidencial na audiência e que a autoridade seja o juiz, o entrevistador não estaria submetido a uma determinação de responder a todas as questões. Dessa forma, fica caracterizado que existem opiniões divergentes a respeito da autonomia do psicólogo no DE. O que prevalece é a ideia de que o entrevistador deve respeitar a hierarquia do Poder Judiciário. Sendo ele um auxiliar da Justiça, deve responder à autoridade do Juiz, podendo intervir, adaptando as questões, mas buscando e garantindo o conteúdo das questões propostas, o que pode ser traduzido por uma autonomia limitada.

Quanto a essa questão, as psicólogas judiciárias relataram suas experiências sobre o que tem ocorrido nas salas de DE em que trabalham. As participantes indicaram que se sentem com autonomia no trabalho, mas respeitam uma inegável hierarquia do Poder Judiciário e do sistema presidencial da audiência. Nesse contexto, a autonomia fica dependente dos operadores com quem elas trabalham. Segundo elas, nem todas as experiências de condução do DE foram livres e autônomas, mas alguns operadores, mais rígidos, exercem um controle maior sobre a atividade. Segundo umas das participantes: "Eu tenho autonomia, mas essa autonomia eu acho que é determinada pelas pessoas com quem eu trabalho." (Psi1). A questão da autonomia também foi compreendida como um "processo" no trabalho em equipe. Dessa maneira, fica claro que a autonomia no DE não é assunto esclarecido e definido entre os trabalhadores. As opiniões diferentes sobre essa questão vão influenciar a forma como o procedimento é executado pela psicóloga e como as relações com os operadores do Direito vão se desenrolar durante a audiência.

\section{b) Funções do DE}

Essa categoria descreve as percepções dos participantes quanto às diferentes funções que o DE pode 
desempenhar nos processos judiciais envolvendo ASI. Enquanto os juízes são unânimes em afirmar que o novo método é relevante e faz muita diferença para os operadores e, principalmente, para a criança, defensores e promotores discordam sobre sua efetividade. Os juízes de direito consideram, de uma maneira geral, que o DE trouxe um avanço significativo na maneira de conduzir audiências em situações de abuso sexual. Esses profissionais comparam a estratégia a suas experiências em audiências tradicionais, em que presenciaram cenas de constrangimento das crianças vítimas diante de seus agressores e/ou de seus representantes (defensores/ advogados). Para os juízes, a audiência tradicional é caracterizada por "formalidade e insensibilidade" (J2), enquanto o DE "é um marco no judiciário" (J4), "uma grande criação, uma grande construção" (J3).

Defensores, promotores e juízes, que concordam com o método e o consideram importante, justificam suas opiniões a partir de dois argumentos: o da produção da prova e o da proteção da vítima. O fato de o DE possibilitar a coleta do depoimento da vítima de uma forma que garanta os direitos do réu (contraditório e ampla defesa), ao mesmo tempo em que busca preservar a criança/adolescente justificam, para estes participantes, a continuidade da utilização da estratégia do DE. Para eles, a produção da prova no DE lhes dá maior "certeza" (D2) e "segurança" (D1) para que possam executar sua tarefa numa circunstância em que, na maior parte dos casos, o "depoimento é a única prova” (D4). No contexto penal, o interesse jurídico é exatamente este: "o profissional tem que saber o que se busca naquela entrevista; que não é uma entrevista de tratamento, e sim de apuração do que aconteceu" (Pro1). Considerando o aspecto de produção de prova, os participantes revelam a importância, no contexto do processo jurídico, do conhecimento de detalhes da situação abusiva, além, é claro, da necessária comprovação desta. Por se tratar deste crime carente de materialidade - o abuso sexual - o depoimento da vítima se faz essencial para que se conheça o que de fato ocorreu. E o DE contribui nesse sentido, possibilitando, numa circunstância acolhedora e mais natural, uma coleta de dados mais fidedigna, que ajuda "a condenar e a absolver" (J3).

Mesmo as psicólogas judiciárias, que apresentam, então, formação diferenciada dos outros participantes, percebem a importância da comprovação do fato alegado. Segundo elas, esse é, afinal, o objetivo primordial do trabalho neste contexto: contribuir para que a criança consiga "fornecer elementos" (Psi1), para o processo. A responsabilização é compreendida como uma necessidade não apenas do sistema de justiça, mas da família da vítima: "a responsabilização é uma resposta pra essa família...porque, se não, não tem sentido passar pelo que ela passou, fazer um boletim de ocorrência, denunciar, a pessoa ser afastada, ela passar por todo um tratamento..." (Psi5).

Entretanto, a maior parte desses profissionais entende que o método é muito mais importante no sentido de proteção da vítima. Os profissionais consideram que, neste aspecto, o DE apresenta uma "diferença enorme" (D1): "Vir em uma audiência falar com pessoas estranhas, numa sala fria até pra nós é uma coisa desgastante... então, uma sala mais aconchegante, com coisas pra crianças, com brinquedos, com objetos da idade delas... a gente percebe que a criança fica mais à vontade e isso certamente não vai contribuir para um trauma a mais..." (D1). Uma promotora destaca que o nome inicial do projeto era exatamente pela proposta de proteção à vítima: "antes era chamado de depoimento sem dano e a ideia era essa, que não houvesse uma revitimização da criança quando fosse ouvida no processo criminal" (Pro5). Para outro promotor, não há dúvidas sobre o quanto a estratégia protege a vítima: "O depoimento sem dano é fundamental porque vai ter esse direcionamento feito com pessoas que têm mais habilidades técnicas pra isso, e para a proteção da criança é algo que não tem como tu quantificar a diferença que existe entre uma oitiva do depoimento sem dano e uma oitiva feita em audiência ou numa delegacia" (Pro2). Ainda que uma coleta de depoimento busque a obtenção de informação sobre o possível abuso, a tendência dos participantes é concordar com o foco do método na questão protetiva. Por isso, questiona um juiz: "se é melhor para a criança, por que não?” (J5).

Não são todos os operadores, contudo, que concordam que o DE proteja as crianças e adolescentes vítimas. Um dos defensores considera que a circunstância do depoimento, ainda que ocorrendo em uma sala especial, continua causando constrangimentos: "elas ficam de cabeça baixa, não querem falar, não falam muito, ficam retraídas" (D2), causando, mesmo assim, danos à criança ou adolescente. "Acho que se deram conta de que ainda assim tem dano...da forma como é feito, eu tenho convicção de que não protege a criança" (D5). Os promotores de justiça, por sua vez, são unânimes e concordam com a questão protetiva presente no $\mathrm{DE}$, ainda que não concordem quanto aos resultados objetivos em termos de produção de prova (Pro3). Ilustrando a importância do método para os dois objetivos, 
um juiz afirma: "o profissional deve ter, ao mesmo tempo, essa preocupação de proteger a criança, mas também no aspecto processual, o que se espera daquele depoimento é colher uma prova adequada" (J1).

No aspecto protetivo, as psicólogas judiciárias enfatizam que o DE contribui para diminuir a necessidade de inúmeras entrevistas com a criança vítima. Além disso, o DE é conduzido por profissionais capacitados em acolher e entrevistar esse público específico, evitando assim a exposição da criança a pessoas que não teriam preparo suficiente. Ainda mais importante, é o fato de que as vítimas são "poupadas do momento da audiência" (Psi1). Numa audiência tradicional, elas ficariam expostas às perguntas de defensores e promotores, ainda que estas perguntas fossem indeferidas pelo juiz. Por estarem no mesmo ambiente, ainda que o juiz considere inadequada ou desnecessária uma questão, o defensor, por exemplo, já proferiu a sua questão e a criança já a escutou, sentindo seus efeitos. As psicólogas, consideram a escuta da criança como indispensável e acreditam que é necessário o depoimento da vítima neste contexto. Nesse sentido, o DE protege por buscar preservar a criança de situações como entrevistas recorrentes, com profissionais despreparados e na "tensionante" (Psi1) situação da audiência tradicional. Além disso, outros aspectos protetivos envolvem orientação de familiares e responsáveis da/pela vítima, escuta desses familiares, os momentos de acolhimento inicial e final com a vítima e encaminhamentos necessários para a rede de atendimento.

\section{c) Condições Técnicas}

Essa categoria aborda as condições do DE, como aspectos do ambiente físico (equipamento e espaço físico) e também questões relacionadas à experiência prática das equipes. Subjacente às necessidades que serão apresentadas nessa categoria, está a opinião de que existe um projeto interessante e apropriado, mas a execução ainda não contempla aspectos necessários: o DE "não tem surtido o efeito desejado" (D4) e precisa ser aperfeiçoado. Porém, de um modo geral, parece que o DE "quando bem orientado e bem conduzido é excelente para todas as partes" (D3) e que "a ideia é excelente, é muito melhor do que a forma antiga, tradicional (D4)". Essas opiniões indicam a necessidade de um aperfeiçoamento do DE para que seja garantido o objetivo central do projeto, que é a real proteção e garantia dos direitos dos envolvidos.

A necessidade de aperfeiçoamento, no que diz respeito a equipamentos e espaço físico, é premente.
Alguns participantes foram mais enfáticos ao afirmar que equipamento velho, estragado e falta de assistência técnica prejudicam o andamento da proposta: "Eu não vi nenhum dia que o equipamento funcionasse assim a pleno" (D3). "Eu acho que não pode ter uma câmera apontada para a criança, ela não pode segurar um microfone para falar, entendeu? Eu acho que tu não pode colocar o ponto no ouvido da pessoa que vai ouvir, de forma que o troço tá sempre caindo" (D4). Outros são menos enfáticos, mas consideram que um aperfeiçoamento tecnológico poderia trazer benefícios ao sistema. Além de queixas claras e consistentes quanto aos problemas com o equipamento, sugestões de melhorias foram apresentadas pelos operadores, como a utilização de várias câmeras em pontos estratégicos da sala, de forma a possibilitar a movimentação da criança, bem como o uso de microfones espalhados pela sala (ambiental). Um defensor sugeriu que os microfones fossem escondidos da criança/adolescente entrevistada: "o ideal seria que a gente conseguisse colocar esse microfone num lugar oculto pra criança não perceber que está sendo ouvida por outras pessoas em uma outra sala" (D1), opinião essa sustentada por outros profissionais entrevistados. Outra defensora tem a mesma opinião (D4): “o equipamento teria que ser imperceptível pra criança, ela não poderia se dar conta que ela está sendo filmada e que o que ela está dizendo está sendo gravado". Entretanto, a defensora (D4) entende que a vítima tem direito de saber que está sendo gravada, mas que este equipamento não precisa ser "ostensivo", "pra que efetivamente a criança se sinta mais adaptada, mesmo que superficialmente". Uma promotora diz que não é a questão de a criança saber, mas sim de ela ter "mais espontaneidade" durante a entrevista (Pro1).

O espaço físico da sala foi criticado por uma defensora: "teria que ter uma sala, praticamente uma brinquedoteca. Não é uma sala, um escritório com tapetinho e meia dúzia de brinquedinhos jogados ali no chão. Teria que ser um espaço com que a criança tivesse contato anteriormente ao dia da audiência" (D4) e um juiz: "mais equipamentos, mais recursos lúdicos (J1). Para um promotor, "a ideia é deixar a criança ou o adolescente mais à vontade, então, quanto mais acolhedor for o ambiente, melhor" (Pro2). Dessa forma, fica claro que as condições tecnológicas, na opinião dos participantes, podem contribuir ou não para uma naturalidade, espontaneidade e para o real acolhimento da vítima.

Quanto à experiência prática das equipes com a metodologia do DE, os participantes relatam que essa 
prática tem sido enriquecedora, tendo em vista que o aperfeiçoamento da técnica com o tempo tem sido visível para todos os operadores do Direito. A fala desta defensora pública ilustra o processo que tem ocorrido nestes cinco municípios: "nós já melhoramos muito, porque no primeiro momento a psicóloga ficava só como intermediária e ficava uma coisa muito artificial... agora não, está melhor porque ela já sabe e vai introduzindo na conversa as perguntas necessárias" (D1). Com o tempo, o ponto eletrônico que permite a comunicação entre as salas de audiência e a do DE passou a ficar em segundo plano, para perguntas específicas do caso, após uma entrevista mais fluida da psicóloga com a vítima. Durante um espaço de tempo em que operadores do Direito e psicóloga judiciária vão desempenhando suas atividades no DE, uma "construção coletiva" (Pro5) vai sendo realizada. A experiência, enquanto algo que perpassa o conjunto de servidores da Justiça e não apenas o entrevistador, é expressada na seguinte fala: "a gente leu bastante, se preparou...agora, todo mundo mais ou menos sabe o que vai acontecer" (Pro5).

Entretanto, existem questionamentos que surgiram a partir dessas experiências. Uma questão crucial levantada mais fortemente pelos defensores públicos diz respeito à imparcialidade no DE. Para estes profissionais, a imparcialidade ainda é algo a ser conquistado. A defensora afirma: "aqui, sempre o réu é culpado" e é preciso uma atuação que não transforme o réu "em um monstro antes de se averiguar o que de fato é. E nem mesmo depois, pois a pessoa pode ter um problema psiquiátrico" (D3). Uma segunda defensora (D4) também percebe uma dificuldade importante nestes termos: para ela, quando a vítima se cala ou "se tranca, começa a indução”. Segundo esta profissional, em seguida ao comportamento de calar-se da criança/ adolescente, a entrevistadora começa a fazer perguntas mais diretas, muitas vezes induzindo as respostas. Nesta mesma direção, a defensora de outro município complementa (D5): "o que a gente nota é uma insistência desnecessária em certas perguntas, o que já é uma indução". Os profissionais de outras categorias não se referiram a esse problema.

Outras questões levantadas pelos profissionais indicaram necessidades percebidas em suas práticas. Um defensor e um juiz apontaram a necessidade de contato prévio com a criança para a construção de um vínculo de confiança, de forma a facilitar o depoimento no momento da audiência. O contato prévio entre operadores do Direito e o entrevistador também foi indicado como sendo necessário para a elaboração mais natural das questões, deixando o ponto eletrônico com menor importância. Para um defensor, "O desconhecimento das necessidades dos questionamentos da defensoria e promotoria" é um aspecto negativo percebido em sua prática (D1) e essa maior comunicação pode contribuir nesse sentido. Também foi citada a questão do tempo entre a revelação e a coleta do depoimento: "o depoimento especial tem que ser feito no momento mais próximo possível da notícia da ocorrência do delito, num ambiente de menor exposição da criança a um dano maior" (J3).

Quanto às experiências das psicólogas judiciárias no DE, as participantes indicam, em primeiro lugar, que a prática da entrevista, a interação com os operadores e o trabalho no contexto judiciário possibilitam um processo mais dinâmico e mais fluido. Ocorre um processo de "construção coletiva" que permite um fluxo mais fácil entre estes trabalhadores e a troca de conhecimentos, num movimento interdisciplinar: Para o aperfeiçoamento do método, também foram destacados os treinamentos realizados tanto com palestrantes internacionais quanto com as técnicas mais experientes, que trazem subsídios empiricamente comprovados para as práticas das psicólogas. Uma das participantes costuma, além de participar dos treinamentos, assistir aos vídeos gravados de suas entrevistas com as vítimas e monitorar seu desempenho, corrigindo aquilo que não estaria adequado (Psi3). Essa oportunidade de autoavaliação teve um impacto positivo em seu trabalho diário, segundo ela.

Ainda que tenham conseguido um importante progresso, as psicólogas judiciárias percebem necessidades nesse trabalho. Uma delas destaca que há necessidade de treinamento para os profissionais do Direito, com informações sobre a atuação diferenciada da Psicologia e sobre questões desenvolvimentais que determinam a intervenção psicológica: "às vezes a gente tem que parar um pouco, dar tempo pra criança, tentar entender porque uma criança não para quieta...uma adolescente é mais fácil, tem mais capacidade de poder compreender...a pergunta é diferente de uma criança menor" (Psi5). Para esta psicóloga, o treinamento dos operadores contribuiria para uma melhor compreensão das ações durante o DE. A outra participante completa: “a gente está acostumada a ter o tempo psicológico, o tempo da pessoa... às vezes há uma tendência a ser um pouquinho mais rápido, por exemplo, os operadores do direito têm certa dificuldade com as pausas, com o silêncio... de poder conseguir manter isso e ficam ansiosos de querer logo saber a resposta" (Psi2). 
Outra necessidade destacada é a de maior articulação entre os setores, dispensando a coleta do depoimento em vários locais e em várias vezes. Nesse sentido, é também muito importante que um esforço seja feito para buscar a antecipação da prova, fazendo com que o DE ocorra o mais próximo possível do evento traumático. Numa articulação entre setores, a vítima não precisaria falar no Conselho Tutelar, nem na delegacia, apenas com os peritos e com os técnicos do DE, que poderiam produzir o depoimento o mais breve possível, evitando o fator do tempo e a exposição da vítima: "aí tu reduz de cinco, seis lugares pra três" (Psi5).

\section{Discussão}

A partir do que foi observado neste estudo, é relevante observar a inserção de psicólogos no contexto de realização do DE. No momento de coleta de dados, eram 24 os municípios que possuíam a sala e os equipamentos para a execução do procedimento de DE no Estado do Rio Grande do Sul e, desses, apenas cinco contavam com profissionais de psicologia em sua equipe. Se comparado à inserção de assistentes sociais (38), observa-se que existe pouco espaço formal no Poder Judiciário para a Psicologia na tomada do DE. Atualmente, conforme dados do Conselho Nacional de Justiça, existem 59 salas de DE em 16 Estados do Brasil, com perspectiva de ampliação (Conselho Nacional de Justiça, 2013).

De um modo geral, a tarefa de coleta de DE foi considerada pelos participantes como não circunscrita a uma determinada área de formação, como a Psicologia ou o Serviço Social. Para grande parte dos participantes, o que mais importa é um treinamento, adequado às especificidades da tarefa, e não exatamente em que curso o profissional obteve a sua graduação. Hoffmeister (2012) também obteve dados sobre a importância dos treinamentos realizados. Alguns participantes consideram que os psicólogos seriam os "mais indicados" para o trabalho. Ainda que o Conselho Federal de Psicologia (2010) tenha se posicionado diferentemente a este respeito e outros autores acreditem que não é tarefa ou papel do psicólogo (Brito, 2008), os participantes deste estudo, em sua maioria, se mostram favoráveis à participação de psicólogos no DE. Alguns operadores manifestaram clara predileção pelo psicólogo, sem descartar, necessariamente, o trabalho de outros profissionais. Ocorre que as bases da formação técnica específica para o trabalho no DE exigem conhecimentos que fazem parte da formação em Psicologia, como técnicas de entrevista, teorias sobre o desenvolvimento humano e personalidade, além de habilidades de acolhimento, conforme declarado pelos próprios participantes e destacados pelo $\mathrm{CNJ}$ em sua recomendação (CNJ, 2010).

O Conselho Federal de Psicologia, em 2010, em resolução que buscou regulamentar a escuta de crianças e adolescentes vítimas de violência sexual, afirmou a necessidade do psicólogo não se subordinar a outras profissões e de ter autonomia em seu trabalho (CFP, 2010). A iniciativa do CFP pode ser compreendida como uma tentativa de observar e preservar a autonomia do psicólogo na tarefa da escuta de crianças. Entretanto, deve-se considerar o contexto judiciário no qual o psicólogo está inserido, marcado por uma hierarquia historicamente mantida. O Código de Processo Penal indica que o juiz é o presidente da audiência, caracterizando o então chamado sistema presidencialista (Brasil, 1941). Em 2008, a Lei 11.690 altera este sistema indicando que as partes poderiam se dirigir diretamente às testemunhas, sem a mediação do juiz (Brasil, 2008). Entretanto, essa alteração não modifica o estatuto presidencial, ou seja, ainda que as partes tenham maior liberdade, ainda há um presidente na audiência e, portanto, uma hierarquia clara e definida neste contexto (Brasil, 1941, 2008).

As experiências dos participantes mostram que a autonomia do entrevistador é variável e parece depender de características pessoais dos operadores com quem ele trabalha: operadores do Direito mais rígidos possibilitariam menos liberdade, enquanto operadores mais flexíveis possibilitariam mais liberdade ao entrevistador. Quando se observa essa autonomia limitada, entende-se que seja limitada por uma hierarquia que é própria, inerente ao Poder Judiciário (Brasil, 1941, 2008), onde o entrevistador está inserido enquanto profissional auxiliar. Ainda que essa hierarquia não seja compreendida por outros setores da sociedade ou por profissionais que trabalham em áreas diferentes da Justiça, é conhecimento de senso comum a sua existência. Dessa forma, uma hierarquia histórica e inegável existe neste contexto, mas não, necessariamente, prejudica a autonomia do profissional que atua em DE, como foi observado neste estudo.

Um aspecto primordial, que parece marcar essa questão, é o quanto o profissional entrevistador pode modificar ou ainda não fazer uma pergunta que lhe foi direcionada pelo juiz. O que se depreende da ideia original de uma escuta mais acolhedora é a de que seria 
necessário um "intérprete” (Dobke, 2001). Ora, dessa forma, pode-se entender que um mero reprodutor das questões do juiz é diferente de um intérprete. Enquanto o primeiro age como alguém que somente executa as ordens, com as mesmas palavras e no mesmo momento que o juiz decide questionar, o segundo deve refazer a questão, adequando-a ao grau de desenvolvimento, habilidade e condições da criança ou adolescente que ali se apresenta. No projeto original do depoimento sem dano, Daltoé Cezar (2007) indica que o técnico responsável pela entrevista irá atuar como um facilitador, realizando as questões de maneira mais compreensível para a criança vítima. Isso significa, portanto, que a pergunta pode e deve ser modificada para ser acessada, compreendida e respondida pelo entrevistado. Tal autonomia foi investigada na categoria das assistentes sociais que trabalham com DE no Brasil, que indicaram ser o entrevistador o responsável por "dar curso ao depoimento" (Hoffmeister, 2012, p.110). Pela experiência dos participantes do presente estudo, o trabalho "em equipe", como uma "construção coletiva", contribuiu para o mútuo entendimento entre as diferentes áreas, em que Psicologia compreende a hierarquia e os papéis estabelecidos no sistema de justiça e, por sua vez, o Direito entende as necessidades da flexibilidade na formulação de questões, no tempo, do silêncio, entre outros aspectos de ordem subjetiva que estão envolvidos na escuta investigativa que caracteriza o DE. Os resultados de Hoffmeister (2012) também indicam que, com o tempo, a interação entre entrevistador e juiz faz com que o relato da vítima se torne "mais livre" (p.110).

A autoridade competente deve ouvir a criança, considerando seu direito à privacidade, intervenção precoce, proteção integral, entre outras (Brasil, 1990a, 1990b, 2009). Neste trabalho, observou-se que, salvo exceções, os participantes indicaram que o DE possibilita tanto a produção da prova, por possibilitar essa oitiva que é direito da criança, quanto a proteção da vítima, assegurando a compreensão de sua condição peculiar de desenvolvimento. Apesar de serem aspectos jurídicos diferentes, situados em especialidades diversas (vara criminal e vara da infância e juventude), as duas funções do DE andam juntas. Além dos direitos da criança e do adolescente previstos no ECA (Brasil, 1990a), a produção da prova deve ser efetuada garantindo-se ao acusado o direito constitucional do contraditório e da ampla defesa (Brasil, 1988), que não pode ser negado tendo em vista a nulidade do processo (Brasil, 1941). Isso significa que se o réu ou o seu representante indicarem a necessidade da ouvida da vítima, não há como lhe negar esse direito, sendo, portanto, necessária a realização de uma audiência, seja na forma de DE ou audiência tradicional (Brasil, 1941). Assim, parece mais protetivo pensar que a presença de um profissional preparado, qualificado e treinado na condução de uma entrevista fidedigna e cuidadosa pode trazer benefícios, em relação à forma de audiência tradicional realizada antes dos anos 2000 no Rio Grande do Sul e ainda hoje em diferentes locais do país.

Um juiz de direito, ainda que lotado numa vara especializada, atende e toma decisões a respeito de casos diferentes todos os dias. O abuso sexual é apenas um tema, dentre vários outros, que são objetos de trabalho e investigação desses profissionais. Não é cabível pensar que esse profissional, com tantas demandas diferentes de trabalho, possa ser um "especialista" em todas essas questões. Por certo, cabe pensar que o juiz pode contar com outros profissionais especializados, com conhecimentos diversos dos dele, que o auxilie em questões tão delicadas como o abuso sexual. Para o DE, é necessário um trabalho interdisciplinar efetivo, além de uma escuta sensível e empática. Para isso, o profissional da saúde pode ser um parceiro importante do judiciário nesta questão (Froner \& Ramires, 2008).

\section{Considerações Finais}

Esta pesquisa investigou como os profissionais que trabalham com o Depoimento Especial no Estado do Rio Grande do Sul percebem esse método de escuta de crianças e adolescentes vítimas de abuso sexual. Ressaltando diferentes aspectos, os profissionais indicaram a importância do treinamento para a execução da tarefa, em detrimento da formação em nível de graduação, e a autonomia como dependente dos operadores do direito com quem o entrevistador trabalha. O DE, com função tanto de produção de prova quanto de proteção da vítima, é percebido como uma experiência construída coletivamente por um conjunto de profissionais, com necessidade de mudança em seus aspectos tecnológicos e também técnicos. A partir dos dados coletados neste estudo, pode-se inferir que a estratégia do DE é um processo em construção, que busca a humanização da coleta do depoimento de crianças e adolescentes vítimas. A construção de um método que possa contribuir para as necessidades da Justiça e para as necessidades do usuário é ainda um desafio para os profissionais que atuam nessa área. Humanizar o sistema de justiça e transformar suas práticas a partir da ética do cuidado 
é algo que somente pode ser realizado na interface entre saberes, no diálogo constante e na sensibilização de todos os atores desse processo. Pessoas e instituições têm à sua frente a missão de superar os embates teóricos e técnicos relativos ao DE e dirigir investimentos na investigação e aperfeiçoamento desse método já reconhecido internacionalmente e recomendado nacionalmente. Por estar em construção, desafios técnicos e tecnológicos se apresentam para o aperfeiçoamento dessa estratégia que está plena de possibilidades de mudança.

As limitações desse estudo incluem, especialmente, a participação exclusiva de profissionais do Estado do Rio Grande do Sul, conhecido no Brasil por seu pioneirismo nessa questão e pela própria propositura da prática (Daltoé César, 2007; Dobke, 2001), o que pode ter levado a vieses nos resultados encontrados. Novos estudos investigando as experiências de profissionais, em nível nacional, incluindo diferentes Estados do país, são necessários para que se obtenha um panorama ampliado de como o método vem sendo conduzido e implementado, além de conhecer melhor suas potencialidades e dificuldades. Percepções e experiências de vítimas e familiares também devem ser objeto de estudo de futuras investigações, a fim de que se possa compreender o impacto do DE de forma mais ampla e em diferentes perspectivas.

\section{Referências}

Bardin, L. (1977). Análise de conteúdo. Lisboa: Edições 70.

Brasil (1941). Decreto-Lei 3.689. Código de Processo Penal. Brasília: Presidência da República. Casa Civil. Subchefia para Assuntos Jurídicos. Retrieved from http:/ /www.planalto.gov.br/ccivil_03/decretolei/del3689.htm

Brasil (1988). Constituição da República Federativa do Brasil de 1988. Brasília: Presidência da República. Casa Civil. Subchefia para Assuntos Jurídicos. Recuperado de http://www.planalto.gov.br/ccivil_03/ constituicao/constituicao.htm

Brasil (1990a). Lei 8.609 de 13 de julho de 1990 - Estatuto da Criança e do Adolescente - ECA. Brasília: Presidência da República. Casa Civil. Subchefia para Assuntos Jurídicos. Recuperado de http:// www.planalto.gov.br/ccivil_03/leis/L8069.htm

Brasil (1990b). Decreto 99210/1990: Promulga a Convenção Sobre os Direitos da Criança. Brasília. Recuperado de http://www.planalto.gov.br/ccivil_03/decreto/1990-1994/D99710.htm

Brasil (2008). Lei 11.690 de 9 de junho de 2008 - Altera o Decreto-Lei 3.689 - Código de Processo Penal. Brasília: Presidência da República. Casa Civil. Subchefia para Assuntos Jurídicos. Recuperado de http://www.planalto.gov.br/ccivil_03/_ato20072010/2008/lei/111690.htm

Brasil (2009). Lei 12.010 de 3 de agosto de 2009. Brasilia: Presidência da República. Casa Civil. Subchefia para Assuntos Jurídicos. Recuperado de http://www. planalto.gov.br/ccivil_03/_Ato2007-2010/2009/ Lei/L12010.htm\#art2

Brasil. Conselho Nacional de Saúde (2012). Diretrizes e normas para pesquisa envolvendo seres bumanos. RESOLUÇÃO No 466, de 12 de dezembro de 2012. Brasília: Diário Oficial da União; Poder Executivo, publicado em 13 jun. 2013. Seção I, p.59-62.

Brito, L. M. T. d. (2008). Diga-me agora... O depoimento sem dano em análise. Psicologia Clínica, 20, 113-125.

Conselho Federal de Psicologia (2010). Resolução CFP 010/2010. Recuperado de http://site.cfp. org.br/wp-content/uploads/2010/07/resolucao2010_010.pdf

Conselho Federal de Psicologia. (2008). CFP é contra "Depoimento Sem Dano". Jornal do Federal, 89, 10-10.

Conselho Federal de Serviço Social - CFESS (2009). Resolução CFESS 554/2009. Recuperado de http://www.cfess.org.br/arquivos/Resolucao_ CFESS_554-2009.pdf

Conselho Nacional de Justiça (2010). Recomendação 33/2010: Recomenda aos tribunais a criação de serviços especializados para escuta de crianças e adolescentes vítimas ou testemunhas de violência nos processos judiciais. Depoimento Especial. Brasília.

Conselho Nacional de Justiça (2013). Curso vai formar 300 profissionais na tomada de depoimento especial de crianças. Recuperado de http://www. cnj.jus.br/noticias/cnj/26232-curso-vai-formar300-profissionais-na-tomada-de-depoimento-especial-de-criancas

Conte, B. S. (2008). Depoimento sem dano: A escuta da psicanálise ou a escuta do direito? Psico, 3(2), 219223. Recuperado de http://revistaseletronicas. 
pucrs.br/ojs/index.php/revistapsico/article/ view/2262

Daltoé Cezar, J. A. (2007). Depoimento sem dano: Uma alternativa para inquirir crianças e adolescentes nos processos judiciais. Porto Alegre: Livraria do Advogado.

Dammeyer, M. D. (1998). The assessment of child sexual abuse allegations: Using research to guide clinical decision making. Behavioral Sciences and the Law, 16, 21-34. Recuperado de http://www.ncbi. nlm.nih.gov/pubmed/9549878

Dobke, V. (2001). Abuso sexual: a inquirição das crianças uma abordagem interdisciplinar. Porto Alegre: Ricardo Lenz Editor.

Estado do Rio Grande do Sul (2010). Mandado de seguranca 5017910-94.2010.404.7100/ RS. Recuperado de http://pfdc.pgr.mpf.gov. $\mathrm{br} /$ temas-de-atuacao/crianca-e-adolescente/depoimento-especial/decisoes-judiciais/ sentenca-trf4-MS50179109420104047100

Faller, K. C. (2007a). Forensic and clinical interviewer roles in child sexual abuse. Em K.C. Faller. Interviewing children about sexual abuse: controversies and best practice. New York: Oxford University Press.

Faller, K. C. (2007b). Documentation of the interview. Em K.C. Faller. Interviewing cbildren about sexual abuse: controversies and best practice. New York: Oxford University Press.

Finnilã-Tuohimaa, K., Santtila, P., Sainio, M., Niemi, P., \& Sandnabba, K. (2005). Connections between experience, beliefs, scientific knowledge and selfevaluated expertise among investigators of child sexual abuse in Finland. Scandinavian Journal of Psychology, 46, 1-10. Recuperado de http://www.ncbi. nlm.nih.gov/pubmed/15660628

Froner, J. P., \& Ramires, V. R. R. (2008). Escuta de crianças vítimas de abuso sexual no âmbito jurídico: Uma revisão crítica da literatura. Paidéia (Ribeirão Preto), 18, 267-278. doi: 10.1590/ S0103-863X2008000200005

Herman, S. (2010). The role of corroborative evidence in child sexual abuse evaluations. Journal of Investigative Psychology and Offender Profiling, 7, 189-212. doi: 10.1002/jip.122

Hoffmeister, M. V. (2012). Tomada de depoimento especial de crianças e adolescentes em situação de abuso sexual:
Desafios à intervenção profissional do assistente social na perspectiva da garantia dos direitos humanos (Dissertação de mestrado). Pontifícia Universidade Católica do Rio Grande do Sul - PUCRS, Porto Alegre.

Huss, M. T. (2011). Psicologia forense: Pesquisa, prática clínica e aplicações. Porto Alegre: Artmed.

Myers, J. E. B. (1998). Legal issues in child abuse and neglect practice. Newbury Park, CA: Sage Publications.

Potter, L. (2010). Violência, vitimização e políticas de redução de danos. Em L. Potter \& C. R. Bittencourt (Eds). Depoimento Sem Dano: Por uma politica criminal de redução de danos. Rio de Janeiro: 2010.

Santos, B. R., \& Gonçalves, I. B. (2008). Depoimento sem medo: Culturas e práticas não revitimizantes - uma cartografia das experiências de tomada de depoimento especial de crianças e adolescentes. São Paulo: Childhood Brasil.

Souza, F. N., Costa, A. P., \& Moreira, A. (2011). Análise de dados qualitativos suportada pelo software webQDA. Atas da VII Conferência Internacional de TIC na Educação: Perspetivas de Inovação, Braga, Portugal.

Stake, R. (1994). Case studies. In N. Denzin \& Y. Lincoln (Eds.). Hanbook of qualitative research (pp.236-247). London: Sage.

Stein, L., Pergher, G. K., \& Feix, L. F. (2009). Desafios da oitiva de crianças e adolescentes: Técnica de entrevista investigativa. Programa Nacional de Enfrentamento da Violência Sexual Contra Crianças e Adolescentes. Secretaria Especial dos Direitos Humanos da Presidência da República. Childhood Brasil. Recuperado de http://www.bancadigital.com.br/sedh/ reader $2 /$ ? $\mathrm{pID}=3$

Tabajaski, B., Paiva, C. V., \& Visnievski, V. M. (2010). Um novo olhar sobre o testemunho infantil. Em L. Potter \& Bitencourt, C. R. (Eds.). Depoimento sem dano: Por uma política criminal de redução de danos. Rio de Janeiro: Lumen.

Wolff, M. P. (2008). Parecer Técnico a Pedido do CFESS sobre "A Metodologia denominada Depoimento Sem Dano, com Ênfase na Análise da Participação do Assistente Social na Equipe de Atuação". Disponível em cress-es. org.br/arquivos/ParecerFavoravel.pdf em $27 \mathrm{de}$ agosto de 2016.

Recebido em: 28/04/2015

Reformulado em: 13/05/2015

Aprovado em: 02/06/2015 
Nota das autoras:

As autoras agradecem ao Conselho Nacional de Desenvolvimento Tecnológico e Científico - CNPq o apoio financeiro à pesquisa.

Sobre as autoras:

Cátula Pelisoli é Psicóloga é Especialista em Psicoterapia Cognitivo Comportamental, Mestre e Doutora em Psicologia, Psicóloga judiciária, membro da Associação Brasileira de Psicologia Jurídica e do Núcleo de Estudos e Pesquisas em Adolescência - NEPA UFRGS.

E-mail: cpelisoli@tj.rs.gov.br

Débora Dalbosco Dell'Aglio é Psicóloga, Professora do Programa de Pós Graduação em Psicologia da Universidade Federal do Rio Grande do Sul, Coordenadora do Núcleo de Estudos e Pesquisas em Adolescência - NEPA UFRGS. E-mail: dddellaglio@gmail.com

Contato com as autoras:

Cátula Pelisoli

Núcleo de Estudos e Pesquisas em Adolescência - NEPA

Rua Ramiro Barcelos, 2600/115

CEP: 90035-003

Porto Alegre-RS, Brasil

Psico-USF, Bragança Paulista, v. 21, n. 2, p. 409-421, mai./ago. 2016 